\title{
Approximating Multisector New Keynesian Models
}

\author{
Carlos Carvalho \\ Central Bank of Brazil \\ PUC-Rio \\ Fernanda Nechio \\ Federal Reserve Bank of San Francisco
}

September 2017

Working Paper 2017-12

http://www.frbsf.org/economic-research/publications/working-papers/wp2017/12

\section{Suggested citation:}

Carvalho, Carlos, Fernanda Nechio. 2017. “Approximating Multisector New Keynesian Models" Federal Reserve Bank of San Francisco Working Paper 2017-12.

https://doi.org/10.24148/wp2017-12

The views in this paper are solely the responsibility of the authors and should not be interpreted as reflecting the views of the Federal Reserve Bank of San Francisco or the Board of Governors of the Federal Reserve System. 


\section{Approximating Multisector New Keynesian Models*}

\author{
Carlos Carvalho \\ Central Bank of Brazil \\ PUC-Rio
}

\author{
Fernanda Nechio \\ Federal Reserve Bank of San Francisco
}

September, 2017 


\section{Introduction}

The macroeconomics literature has provided substantial evidence of significant heterogeneity in the average frequencies with which firms in different sectors of the economy change their prices, both in the U.S. and in other countries (e.g., Blinder et al., 1998, Bils and Klenow, 2004, Nakamura and Steinsson, 2008, and Klenow and Malin, 2011 for the U.S. economy; Dhyne et al., 2006, and references cited therein for the euro area).

The literature has also shown that accounting for this heterogeneity matters for the dynamic properties of New Keynesian economies (e.g., Carvalho, 2006, Nakamura and Steinsson, 2010, Carvalho and Nechio, 2011 and Pasten, Schoenle and Weber, 2016). Models that allow for heterogeneity in frequency of price adjustments yield substantially different dynamics for aggregate variables than models that assume that firms adjust prices at a common (average) frequency. In response to monetary shocks, for example, heterogeneous multisector models feature much larger and more persistent real effects than one-sector economies with similar average degrees of nominal rigidities. Heterogeneity in price stickiness also has implications for optimal monetary policy (e.g., Aoki, 2001 and Eusepi, Hobijn and Tambalotti, 2011). ${ }^{1}$

Working with large-scale multisector models, however, is computationally costly. As a consequence, while one can find several calibrated multisector models in the literature, the set of papers that entertain estimating such large-scale models is much more limited (exceptions include, for example, Carvalho and Lee, 2011 and Bouakez, Cardia and Ruge-Murcia, 2009).

In this paper we show how a large-dimension multisector economy can be approximated by a three-sector model that, aside from the number of sectors, features the same model ingredients as the original economy. In particular, we show that for a suitably chosen distribution of price stickiness, aggregate variables in the three-sector model feature similar dynamics than the corresponding variables in the original model. A comparison of the impulse response functions (IRFs) of the main aggregate variables in response to monetary and technology shocks shows that the three-sector economy follows the dynamic properties of the original (larger-scale) model extremely closely.

The empirical evidence shows that the distribution of price stickiness is highly asymmetric, and with a long right tail. Therefore, there is a larger mass of sectors adjusting more frequently and a smaller mass adjusting very infrequently. These features are well summarized by five moments of the distribution, namely; ( $i$ ) average frequency of price changes, (ii) cross-sectional average of durations of price spells, (iii) cross-sectional standard deviation of durations of price spells, (iv) the cross-sectional skewness of durations of price spells, and $(v)$ cross-sectional

\footnotetext{
${ }^{1}$ These papers also study the effects of sector-specific shocks. Our approach, on the other hand, focuses on aggregate shocks as sectors are solely identified by their price stickiness parameter.
} 
kurtosis of durations of price spells.

Our approximation strategy entails constructing an artificial small-scale distribution of price rigidity that matches the same shape features of the original one. More specifically, given these five moments of the original distribution of price stickiness, we build a three-sector distribution

by choosing sectoral weights and price adjustment frequencies such that both the approximate and the original distributions share the same aforementioned five moments.

We apply our approximation to the U.S. distribution of price stickiness derived from Nakamura and Steinsson (2008), as well as to artificially-generated arbitrary distributions of price rigidity. We test the performance of our approximation using the dynamic stochastic general equilibrium (DSGE) model presented in Carvalho and Nechio (2016). The model features a multisector economy where heterogeneity in the frequency of price adjustment is the key source of heterogeneity.

The results show that our approximation performs extremely well. In particular, three-sector economies parameterized with distributions of price stickiness that match the five aforementioned moments yield IRFs to monetary and technology shocks that are very close to the ones obtained in the original economies. These results hold for approximations based on both the U.S. distribution and on the artificially-generated arbitrary distributions of price rigidity.

\section{A three-sector approximation}

The vast literature that studies pricing dynamics agrees on some key features of the distribution of price changes. It points to sizable heterogeneity in frequency of price adjustment across sectors of the economy, with some sectors adjusting prices very frequently, while some others taking much longer. The literature also shows that the distribution of price adjustments is highly asymmetric and right-skewed, with a right tail that is much longer than the left one (see, for example Figures 1 of Bils and Klenow, 2004 and Nakamura and Steinsson, 2010). Therefore, the shape of the distribution is such that the sectors that adjust more often account for a larger share of overall consumption expenditures, while sectors that adjust very infrequently account for a much reduced share of these expenditures.

These features of the distributions of price stickiness are important in determining the dynamics of aggregate variables in New Keynesian models (e.g., Carvalho, 2006, Nakamura and Steinsson, 2010, and Carvalho and Nechio, 2011). In addition, Carvalho and Schwartzman (2015) show that, under some conditions, moments of the distribution of price stickiness are sufficient statistics for the real effects of nominal shocks.

Therefore, in order to approximate larger-scale economies with smaller-scale ones, one should 
construct an artificial distribution of price stickiness that mimics the properties of the original distribution. Given the empirical evidence on the skewness and the long tail of the original distribution, this implies that both the approximate and the original distributions should exhibit similar high-order moments.

To that end, we calculate the following moments of the original distribution of price stickiness:

(i) Average frequency of price changes:

$\bar{\alpha}=\sum_{s=1}^{S} f_{s} \alpha_{s}$

(ii) Cross-sectional average of the expected durations of price spells:

$\bar{d} \equiv \sum_{s=1}^{S} f_{s} \alpha_{s}^{-1}$

(iii) Cross-sectional standard deviation of the expected durations of price spells:

$\sigma_{d}=\sqrt{\sum_{s=1}^{S} f_{s}\left(\alpha_{s}^{-1}-\bar{d}\right)^{2}}$

(iv) Skewness of the cross-sectional distribution of expected durations of price spells:

$\mathcal{S}_{d}=\frac{1}{\sigma_{d}^{3}} \sum_{s=1}^{S} f_{s}\left(\alpha_{s}^{-1}-\bar{d}\right)^{3}$,

(v) Kurtosis of the cross-sectional distribution of expected durations of price spells:

$\mathcal{K}_{d}=\frac{1}{\sigma_{d}^{4}} \sum_{s=1}^{S} f_{s}\left(\alpha_{s}^{-1}-\bar{d}\right)^{4}$

where, for each sector $s \in\{1, \ldots, S\}, f_{s}$ stands for sector-s expenditure share and $\alpha_{s}$ stands for sector-s frequency of price adjustment.

To obtain an artificial distribution that mimics the properties of the original one, we construct a three-sector approximate distribution that matches the above five moments of the original distribution. More specifically, we choose two sectoral weights and three frequencies of price changes for the three-sector distribution such that both the approximate and the original distributions share the same five moments above.

To assess our approximation based on this moment-matching approach, we rely on multisector model of Carvalho and Nechio (2016) and compare the dynamics of aggregate variables in the original (large-scale) multisector economies to the dynamics of the corresponding variables in the three-sector economies which feature approximate distributions of price stickiness.

\section{Multisector New Keynesian model}

Carvalho and Nechio (2016)'s multisector DSGE model features identical infinitely-lived consumers that supply labor and capital to intermediate firms that they own, invest in a complete 
set of state-contingent financial claims, and consume a final good. The latter is produced by competitive firms that bundle varieties of intermediate goods. The monopolistically competitive intermediate firms that produce these varieties are divided into sectors that only differ in their frequency of price changes. Labor and capital are the only inputs in the production of intermediate goods and can be reallocated freely across firms in the same sector but cannot move across sectors, i.e., factors are sector-specific. ${ }^{2}$ Production of intermediate goods exhibits constant returns to scale and is subject to technology shocks. The model is closed by assuming that the growth rate of nominal aggregate demand follows a first-order autoregressive, $A R(1)$, process, thus, leaving monetary policy implicit. ${ }^{3}$

Aside from the distribution of price stickiness, which we detail in the next two sections, we parameterize the model as in Carvalho and Nechio (2016) and, unless otherwise stated, keep those parameters unchanged throughout the paper. For brevity, we provide some key ingredients of the model and parameterization details in Appendix A.

\section{Approximating the U.S. empirical distribution}

In this section we resort to the available microeconomic evidence on price rigidity in the U.S. to pin down the distribution of price rigidity across sectors. In particular, we rely on the statistics on the frequency of regular price changes - those that are not due to sales or product substitutions - reported by Nakamura and Steinsson (2008) and apply our approximation to a distribution of price stickiness of 67 expenditure classes of goods and services. ${ }^{4}$ In the model, each class is identified with a sector.

Following the approach described in Section 2, we construct a three-sector approximate price stickiness distribution. The original and the artificial distributions are such that the average frequency of price changes equals 0.2 (which implies prices changing, on average, once every 4.7 months), the cross-sectional average of durations of price spells equals 11.9 months, the crosssectional standard deviation of durations of price spells equals 9.3 months, the cross-sectional skewness of durations of price spells equals 0.7 months, and the cross-sectional kurtosis of

\footnotetext{
${ }^{2}$ In our robustness analysis, we consider two other versions of this DSGE economy that differ in the assumptions about the mobility of factor inputs. Results are qualitatively unchanged.

${ }^{3}$ In the robustness Section 6, we consider alternative specifications for monetary policy and results are qualitatively unchanged.

${ }^{4}$ More specifically, Nakamura and Steinsson (2008) report statistics for 272 entry level items (ELIs) identified by a code with two letters and three numbers. We drop the ELI "Girls' Outerwear," for which the reported frequency of regular price changes is zero, and aggregate statistics up according to the two-letter code, which yields a distribution with 67 expenditure classes of goods and services. Expenditure weights are renormalized to sum to unity. In our robustness analysis in Section 6, we apply our approximation directly to the original distribution from Nakamura and Steinsson (2008). Results are qualitatively unchanged.
} 
durations of price spells equals 2.5 months.
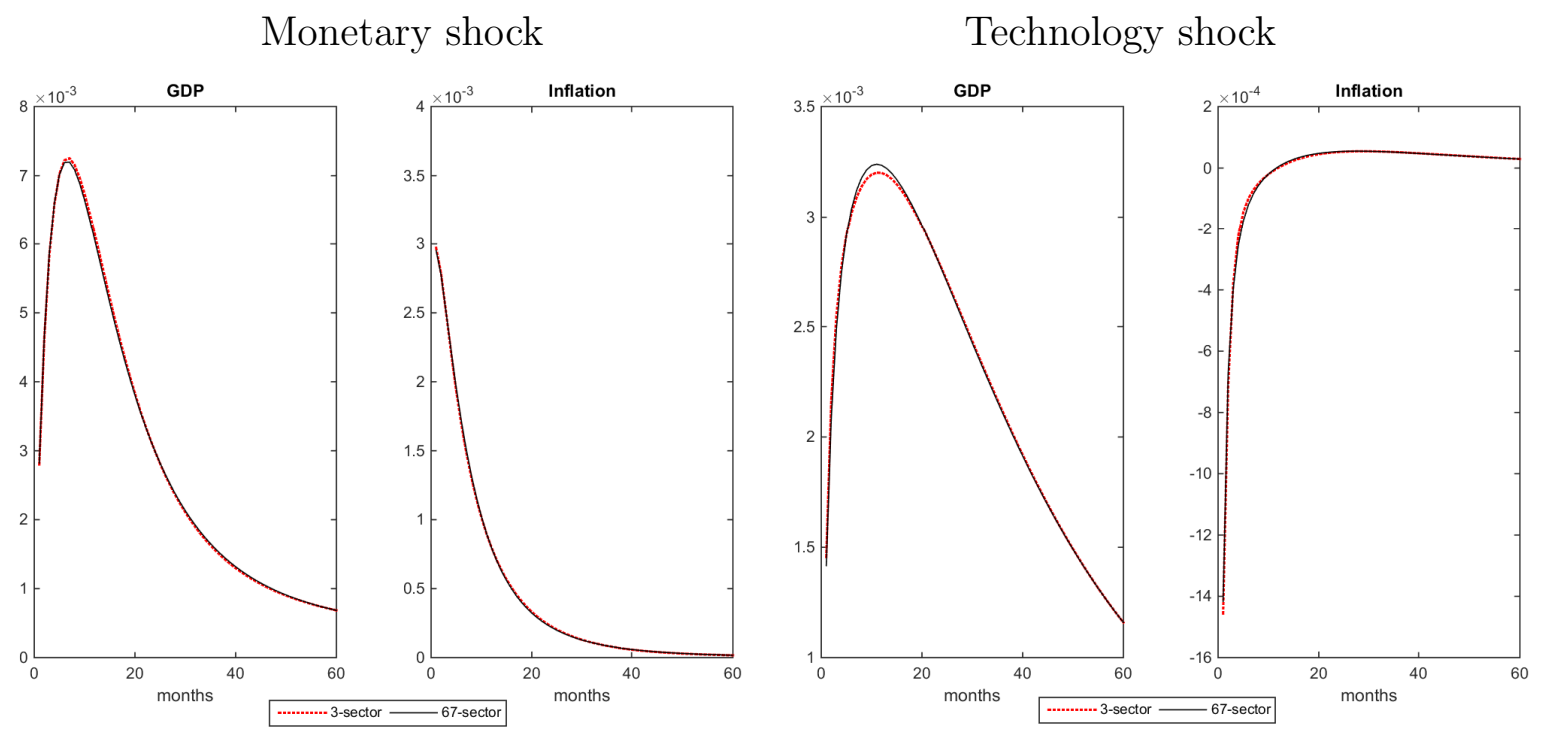

Figure 1: Impulse response functions in the 67-sector and the approximate three-sector economies to monetary and technology shocks.

Figure 1 shows the IRFs to a monetary and a technology shock in the 67-sector model and in the approximate three-sector model. The panels show that for both monetary and technology shocks, the three-sector model parameterized with the approximate distribution does a great job in replicating the original economies' responses of output and inflation to shocks. For brevity, the figure only reports the IRFs for real GDP and inflation. Results for other aggregate variables are reported in Appendix Figures A1 and A2.

\section{$5 \quad$ Approximating arbitrary distributions}

In this section we consider our approximation from artificially-generated distributions of price stickiness. To that end, we construct 67 -sector distributions in which both the frequency of price adjustment and the sectoral weight are chosen arbitrarily. In particular, we start by constructing a vector of 67 frequencies of price changes that ranges from 0.999 to 0.008 , declining in equal steps. Therefore, in this artificial 67 -sector distribution, price changes range from, on average, once a month, in the most flexible sector, to once every 120 months, in the stickiest sector. Next, we associate sets of arbitrary sectoral weights to this vector of frequencies. More specifically, we generate sectoral weights from a Beta distribution in which both shape parameters range from 0.5 to 10 , in incremental steps of 0.25 . This combination of shape parameters yields a set of 1521 arbitrary vectors of sectoral weights. Finally, each vector of weights is paired with the arbitrary vector of frequencies of price changes. 
Turning to the approximation, for each arbitrary (67-sector) distribution, we calculate the five empirical moments of Section 2 and obtain the corresponding approximate three-sector distribution. Next, we parameterize the DSGE model under the original and its approximate distributions, and compare IRFs to monetary and technology shocks.

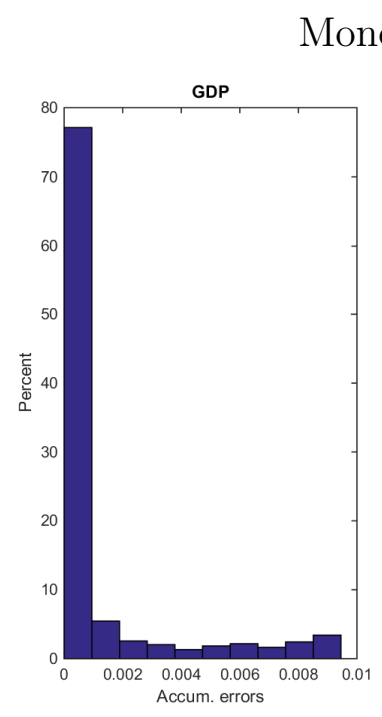

Monetary shock

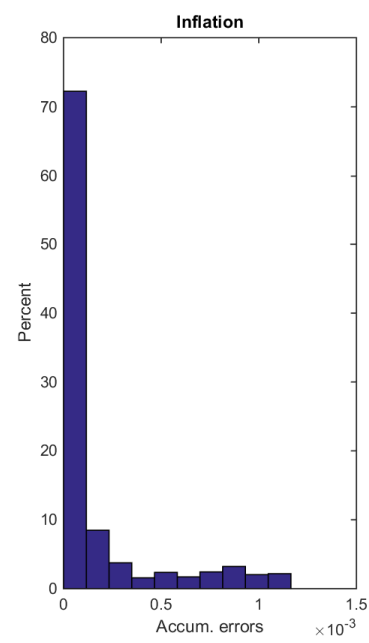

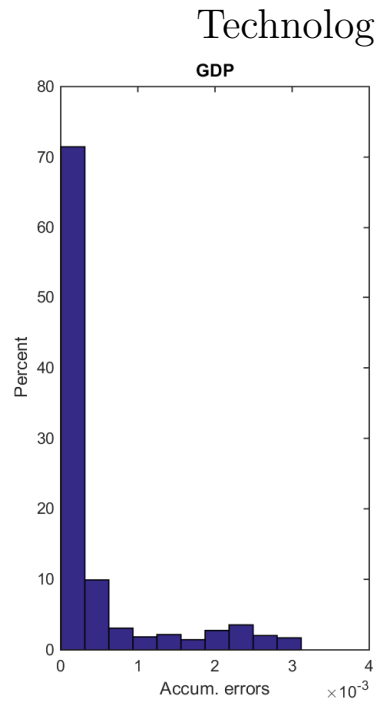

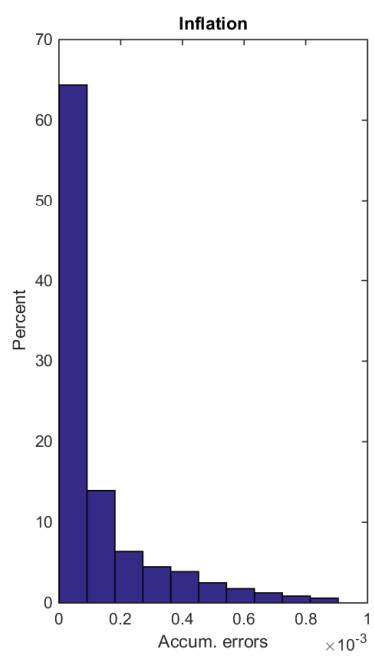

Figure 2: Distribution of the cumulative approximation errors in response to monetary and technology shocks.

For each variable, we calculate the sum (over time) of the difference between the IRFs of the original and the approximate models. This yields a distribution of the cumulative approximation errors for each aggregate variable. ${ }^{5}$

Figure 2 shows the histograms of the accumulated approximation errors for real GDP and inflation in response to monetary and technology shocks. The figure shows that the approximation performs remarkably well, with accumulated errors in the order of $10^{-3}$ to $10^{-2}$. Appendix Figures A3 and A4 show similar results for other aggregate variables.

\section{Robustness}

To assess the robustness of our findings, we consider a set of alternative model assumptions and distributions of price stickiness.

In particular, we consider two alternative assumptions about the specificity of factor inputs. More specifically, while in the benchmark results we assume that labor and capital are specific

\footnotetext{
${ }^{5}$ We also consider other metrics to evaluate how similar the IRFs from the original and the approximate models are, such as the half-lives of the responses and cumulative impulse responses. The conclusions are similar to those illustrated in Figure 2. Results are available upon request.
} 
to the sector, we also entertain a version of the model with economy-wide factors (i.e., labor and capital can move across firms and sectors), and a version in which factors are firm specific (i.e., factors cannot move across firms nor sectors). ${ }^{6,7}$ We also entertain labor-only versions of the three models. In addition, we consider versions of these models with alternative Taylor rules. For all these model variations, we compare original and approximate impulse response functions using the empirical distribution of price stickiness of Section 4 and the arbitrary distributions of Section 5. Finally, we consider two alternative empirical distributions of price stickiness. First, we approximate directly from the full 271-category distribution from Nakamura and Steinsson (2008). Second, we also apply our approximation approach to the 350-category distribution from Bils and Klenow (2004). In all cases our findings confirm that the approximate distribution does a great job in replicating the impulse response functions of the original economies. For brevity, results are reported in an extended version of this paper (Carvalho and Nechio, 2017).

\section{Conclusion}

A calibrated model with a suitably chosen three-sector distribution of price stickiness can closely approximate the dynamic properties of large-scale New Keynesian multisector models. This result should prove useful to the literature that takes into account heterogeneity of price stickiness in DSGE models. In particular, it should allow for the estimation of such models at a much reduced computational cost.

\section{References}

Aoki, Kosuke. 2001. "Optimal monetary policy responses to relative-price changes." Journal of Monetary Economics, 48(1): 55 - 80.

Bils, Mark, and Peter J. Klenow. 2004. "Some Evidence on the Importance of Sticky Prices." Journal of Political Economy, 112(5): 947-985.

Blinder, Alan S., Elie R. D. Canetti, David E. Lebow, and Jeremy B. Rudd. 1998. Asking About Prices: A New Approach to Understanding Price Stickiness. Russell Sage Foundation.

\footnotetext{
${ }^{6}$ The former version is a common assumption in the literature, while the latter was first explored in Woodford (2003) and Woodford (2005).

${ }^{7}$ See Appendix A for additional details.
} 
Bouakez, Hafedh, Emanuela Cardia, and Francisco Ruge-Murcia. 2009. "The Transmission of Monetary Policy in a Multi-sector Economy." International Economic Review, 50: $1243-1266$.

Calvo, Guillermo. 1983. "Staggered Prices in a Utility Maximizing Framework." Journal of Monetary Economics, 12: 383-398.

Carvalho, Carlos. 2006. "Heterogeneity in Price Stickiness and the Real Effects of Monetary Shocks." Frontiers of Macroeconomics, 2(1): 1-58.

Carvalho, Carlos, and Felipe Schwartzman. 2015. "Selection and monetary non-neutrality in time-dependent pricing models." Journal of Monetary Economics, 76: 141 - 156.

Carvalho, Carlos, and Fernanda Nechio. 2011. "Aggregation and the PPP Puzzle in a Sticky-Price Model." The American Economic Review, 101(6): pp. 2391-2424.

Carvalho, Carlos, and Fernanda Nechio. 2016. "Factor specificity and real rigidities." Review of Economic Dynamics, 22: 208 - 222.

Carvalho, Carlos, and Fernanda Nechio. 2017. "Approximating Multisector New Keynesian Models - Extended Version." Available at http://www.frbsf.org/ economic-research/files/wp2017-12_appendix.pdf.

Carvalho, Carlos, and Jae Won Lee. 2011. "Sectoral price facts in a sticky-price model." Federal Reserve Bank of New York Staff Reports 495.

Chari, V. V., Patrick J. Kehoe, and Ellen R. Mcgrattan. 2000. "Sticky Price Models of the Business Cycle: Can the Contract Multiplier Solve the Persistence Problem?" Econometrica, 68(5): 1151-1179.

Dhyne, Emmanuel, Luis J. Alvarez, Herve Le Bihan, Giovanni Veronese, Daniel Dias, Johannes Hoffmann, Nicole Jonker, Patrick Lunnemann, Fabio Rumler, and Jouko Vilmunen. 2006. "Price Changes in the Euro Area and the United States: Some Facts from Individual Consumer Price Data." Journal of Economic Perspectives, 20(2): 171-192.

Eusepi, Stefano, Bart Hobijn, and Andrea Tambalotti. 2011. "CONDI: A Cost-ofNominal-Distortions Index." American Economic Journal: Macroeconomics, 3(3): 53-91.

Hobijn, Bart, and Fernanda Nechio. 2017. "Sticker shocks: using VAT changes to estimate upper-level elasticities of substitution." Federal Reserve Bank of San Francisco Working Paper Series 2015-17. 
Klenow, Peter J., and Benjamin A. Malin. 2011. "Microeconomic Evidence on PriceSetting." In Handbook of Monetary Economics. Vol. 3, , ed. Benjamin M. Friedman and Michael Woodford, Chapter 6, 231-284. Elsevier.

Mankiw, N. Gregory, and Ricardo Reis. 2002. "Sticky Information versus Sticky Prices: A Proposal to Replace the New Keynesian Phillips Curve." The Quarterly Journal of Economics, 117(4): 1295-1328.

Nakamura, Emi, and Jón Steinsson. 2008. "Five Facts about Prices: A Reevaluation of Menu Cost Models." The Quarterly Journal of Economics, 123(4): 1415-1464.

Nakamura, Emi, and Jòn Steinsson. 2010. "Monetary Non-neutrality in a Multisector Menu Cost Model." The Quarterly Journal of Economics, 125(3): pp. 961-1013.

Pasten, Ernesto, Raphael Schoenle, and Michael Weber. 2016. "The Propagation of Monetary Policy Shocks in a Heterogeneous Production Economy." Available at http:// people.brandeis.edu/ schoenle/research/networks_monetary.pdf.

Woodford, Michael. 2003. Interest and Prices: Foundations of a Theory of Monetary Policy. Princeton University Press.

Woodford, Michael. 2005. "Firm-Specific Capital and the New Keynesian Phillips Curve." International Journal of Central Banking, 1(2). 


\section{Appendix to "Approximating Multisector New Keynesian Models"}

\section{A Carvalho and Nechio (2016)'s multisector DSGE with sector-specific factors}

The representative consumer maximizes:

$$
E_{0} \sum_{t=0}^{\infty} \beta^{t}\left(\frac{C_{t}^{1-\sigma}-1}{1-\sigma}-\sum_{s=1}^{S} \omega_{s} \frac{N_{s, t}^{1+\gamma}}{1+\gamma}\right)
$$

subject to the flow budget constraint:

$$
P_{t} C_{t}+P_{t} I_{t}+E_{t}\left[\Theta_{t, t+1} B_{t+1}\right] \leq \sum_{s=1}^{S} W_{s, t} N_{s, t}+B_{t}+T_{t}+\sum_{s=1}^{S} Z_{s, t} K_{s, t}
$$

the law of motion for the stocks of sector-specific capital:

$$
\begin{aligned}
K_{s, t+1} & =(1-\delta) K_{s, t}+\Phi\left(I_{s, t}, K_{s, t}\right) I_{s, t}, \forall s \\
\Phi\left(I_{s, t}, K_{s, t}\right) & =\Phi\left(\frac{I_{s, t}}{K_{s, t}}\right)=1-\frac{1}{2} \kappa \frac{\left(\frac{I_{s, t}}{K_{s, t}}-\delta\right)^{2}}{\frac{I_{s, t}}{K_{s, t}}} \\
I_{s, t} & \geq 0, \forall s
\end{aligned}
$$

and a standard "no-Ponzi" condition. $E_{t}$ denotes the time- $t$ expectations operator, $C_{t}$ is consumption of the final good, $N_{s, t}$ denotes total labor supplied to firms in sector $s, W_{s, t}$ is the associated nominal wage rate, and $\omega_{s}$ is the relative disutility of supplying labor to sector $s$. $I_{s, t}$ denotes investment in sector-s capital, $I_{t} \equiv \sum_{s=1}^{S} I_{s, t}, K_{s, t}$ is capital supplied to firms in sector $s$, and $Z_{s, t}$ is the associated nominal return on capital.

The final good can be used for either investment or consumption, and sells at the nominal price $P_{t} . B_{t+1}$ accounts for the state-contingent value of the portfolio of financial securities held by the consumer at the beginning of $t+1$. Under complete financial markets, agents can choose the value of $B_{t+1}$ for each possible state of the world at all times, subject to the no-Ponzi condition and the budget constraint. $T_{t}$ stands for profits received from intermediate firms. The absence of arbitrage implies the existence of a nominal stochastic discount factor $\Theta_{t, t+1}$ that prices in period $t$ any financial asset portfolio with state-contingent payoff $B_{t+1}$ at the 
beginning of period $t+1 .^{8} \beta$ is the time-discount factor, $\sigma^{-1}$ denotes the intertemporal elasticity of substitution, $\gamma^{-1}$ is the Frisch elasticity of labor supply, $\delta$ is the rate of depreciation. Finally, the adjustment-cost function, $\Phi($.$) , is specified as in Chari, Kehoe and Mcgrattan (2000), where$ $\Phi$ is convex and satisfies $\Phi(\delta)=1, \Phi^{\prime}(\delta)=0$, and $\Phi^{\prime \prime}(\delta)=-\frac{\kappa}{\delta}$.

A representative competitive firm produces the final good, which is a composite of varieties of intermediate goods. Monopolistically competitive firms produce such varieties. The latter firms are divided into sectors indexed by $s \in\{1, \ldots, S\}$, each featuring a continuum of firms. Sectors differ in the degree of price rigidity, as we detail below. Overall, firms are indexed by their sector $s$, and are further indexed by $j \in[0,1]$. The distribution of firms across sectors is given by sectoral weights $f_{s}>0$, with $\sum_{s=1}^{S} f_{s}=1$.

The final good is used for both consumption and investment by combining the intermediate varieties. More specifically, the representative final-good-producing firm solves:

$$
\begin{aligned}
& \max P_{t} Y_{t}-\sum_{s=1}^{S} f_{s} \int_{0}^{1} P_{s, j, t} Y_{s, j, t} d j \\
& \text { s.t. } \quad Y_{t}=\left(\sum_{s=1}^{S} f_{s}^{\frac{1}{\eta}} Y_{s, t}^{\frac{\eta-1}{\eta}}\right)^{\frac{\eta}{\eta-1}} \text { and } \quad Y_{s, t}=\left(f_{s}^{\frac{\theta-1}{\theta}} \int_{0}^{1} Y_{s, j, t}^{\frac{\theta-1}{\theta}} d j\right)^{\frac{\theta}{\theta-1}},
\end{aligned}
$$

where $Y_{t}$ is the final good, $Y_{s, t}$ is the aggregation of sector- $s$ intermediate goods, and $Y_{s, j, t}$ is the variety produced by firm $j$ in sector $s$. The parameters $\eta \geq 0$, and $\theta>1$ are, respectively, the elasticity of substitution across sectors and the elasticity of substitution within sectors. $P_{t}$ is the price of the final good, $P_{s, t}$ is the price index of sector- $s$ intermediate goods, and $P_{s, j, t}$ is the price charged by firm $j$ from sector $s$.

Monopolistically competitive firms produce varieties of the intermediate good by employing capital and labor. For analytical tractability, we assume that intermediate firms set prices as in Calvo (1983). The frequency of price changes varies across sectors, and it is the only source of (ex-ante) heterogeneity.

In each period, each firm $j$ in sector $s$ changes its price independently with probability $\alpha_{s}$, and when it does, it chooses $X_{s, j, t}$ to solve:

$$
\begin{array}{r}
\max E_{t} \sum_{l=0}^{\infty} \Theta_{t, t+l}\left(1-\alpha_{s}\right)^{l}\left[X_{s, j, t} Y_{s, j, t+l}-W_{s, t+l} N_{s, j, t+l}-Z_{s, t+l} K_{s, j, t+l}\right] \\
\text { s.t. } Y_{s, j, t}=\left(\frac{P_{s, j, t}}{P_{s, t}}\right)^{-\theta}\left(\frac{P_{s, t}}{P_{t}}\right)^{-\eta} Y_{t} \quad \text { and } \quad Y_{s, j, t}=A_{t}\left(K_{s, j, t}\right)^{1-\chi}\left(N_{s, j, t}\right)^{\chi}
\end{array}
$$

where $\chi$ is the elasticity of output with respect to labor. The productivity shock $A_{t}$ evolves

\footnotetext{
${ }^{8}$ To avoid cluttering the notation, we omit explicit reference to the different states of nature.
} 
according to $\log A_{t}=\rho_{A} \log A_{t-1}+\sigma_{\varepsilon_{a}} \varepsilon_{a, t}$, where $\varepsilon_{a, t}$ is a zero-mean, unit-variance $i . i$.d. shock, and $\rho_{A} \in[0,1)$ is the shock persistence.

For brevity, we refrain from presenting all equilibrium conditions and refer the reader to Carvalho and Nechio (2016) for details. We note that as a direct implication of the assumption of sector specificity in capital and labor markets, firm's real marginal costs are equalized at the sectoral level.

To close the model, as in the benchmark version of the models presented in Carvalho and Nechio (2016), we assume that the growth rate of nominal aggregate demand follows a firstorder autoregressive, $A R(1)$, process, thus, leaving monetary policy implicit. ${ }^{9}$ Denoting nominal aggregate demand by $M_{t} \equiv P_{t} Y_{t}$ :

$$
\Delta m_{t}=\rho_{m} \Delta m_{t-1}+\sigma_{\varepsilon_{m}} \varepsilon_{m, t}
$$

where $m_{t} \equiv \log \left(M_{t}\right), \rho_{m}$ determines the autocorrelation in nominal aggregate demand growth, and $\varepsilon_{m, t}$ is a purely monetary, uncorrelated, zero-mean, unit-variance i.i.d. shock.

The model is solved and analyzed using a loglinear approximation around a zero-inflation steady state.

\section{A.1 Alternative factor mobility specifications}

To consider the firm-specific and the economy-wide multisector economy, one needs to reformulate the consumers' and intermediate firms' problems. In the firm-specific case, in equilibrium, returns to capital and labor are firm-specific. In contrast, in the economy-wise case, capital and labor returns are equalized across firms and sectors. Therefore, differently from the model of Section 3, real marginal costs are firm-specific, while in the economy-wide model, firms' real marginal costs are equalized across firms and sectors. For additional details about all three models, see Carvalho and Nechio (2016).

\section{A.2 Parameterization}

As described in Section 4, we use the statistics on the frequency of regular price changes those that are not due to sales or product substitutions — reported by Nakamura and Steinsson (2008). More specifically, the U.S. distribution of price stickiness we consider consists of weights and frequencies of price changes for 67 expenditure classes of goods and services. ${ }^{10}$ In the model,

\footnotetext{
${ }^{9}$ This is a common assumption in the literature (e.g. Mankiw and Reis, 2002).

${ }^{10}$ Note that we aggregate the original 272 categories from Nakamura and Steinsson (2008) up into their corresponding 67 expenditure classes of goods and services. To do so, we discard the category "Girls' Outerwear,"
} 
each class is identified with a sector.

We set the remaining parameters of the model as in Carvalho and Nechio (2016) and, unless otherwise stated, keep those parameters unchanged in the different variants of the models entertained below.

In particular, we set the intertemporal elasticity of substitution $\sigma^{-1}$ to $1 / 2$, the (inverse) labor supply elasticity $\gamma$ to 0.5 , the elasticity of output with respect to labor to $\chi=2 / 3$, and the consumer discount factor $\beta$ such that it implies a time-discount rate of $4 \%$ per year.

We set the elasticity of substitution between varieties of the same sector to $\theta=7$. Relying on the estimates provided by Hobijn and Nechio (2017), we set the elasticity of substitution across sectors to unity, $\eta=1$ (i.e. the aggregator that converts sectoral into final output is Cobb-Douglas).

To specify the process for nominal aggregate demand, the literature usually relies on estimates based on nominal GDP, or on monetary aggregates such as M1 or M2. With quarterly data, estimates of $\rho_{m}$ typically fall in the range of 0.4 to 0.7 , which maps into a range of roughly $0.75-0.90$ at a monthly frequency. ${ }^{11}$ We set $\rho_{m}=0.8$, and the standard deviation of the shocks $\sigma_{\varepsilon_{m}}=0.6 \%$ (roughly $1 \%$ at a quarterly frequency), in line with the same estimation results. For technology shocks, we set $\rho_{a}=0.965$ and the standard deviation of the shocks $\sigma_{\varepsilon_{m}}=0.6 \%$ (roughly $1 \%$ at a quarterly frequency).

Finally, we calibrate investment adjustment costs, $\kappa$, so that each model roughly matches the standard deviation of investment relative to the standard deviation of GDP in the data. For that, we consider monetary and technology shocks one at a time. When analyzing the response to monetary shocks, we set $\kappa$ to 40 , while when analyzing the response to technology shocks, we set $\kappa$ to 15 . The remaining parameter values are unchanged from the baseline parameterization when considering one or the other shock.

for which the reported frequency of regular price changes is zero, aggregate up based on the 67 expenditure classes, and renormalize the expenditure weights to sum to unity. The frequency of price changes for each expenditure class is obtained as the weighted average of the frequencies for the underlying categories, using the expenditure weights provided by Nakamura and Steinsson (2008). Expenditure-class weights are given by the sum of the expenditure weights for those categories. As an example of what this aggregation entails, the resulting "New and Used Motor Vehicles" class consists of the categories "Subcompact Cars", "New Motorcycles", "Used Cars", "Vehicle Leasing" and "Automobile Rental"; the "Fresh Fruits" class comprises four categories: "Apples", "Bananas", "Oranges, Mandarins etc." and "Other Fresh Fruits."

${ }^{11}$ See, for instance, Mankiw and Reis (2002). 


\section{B Supplementary figures}
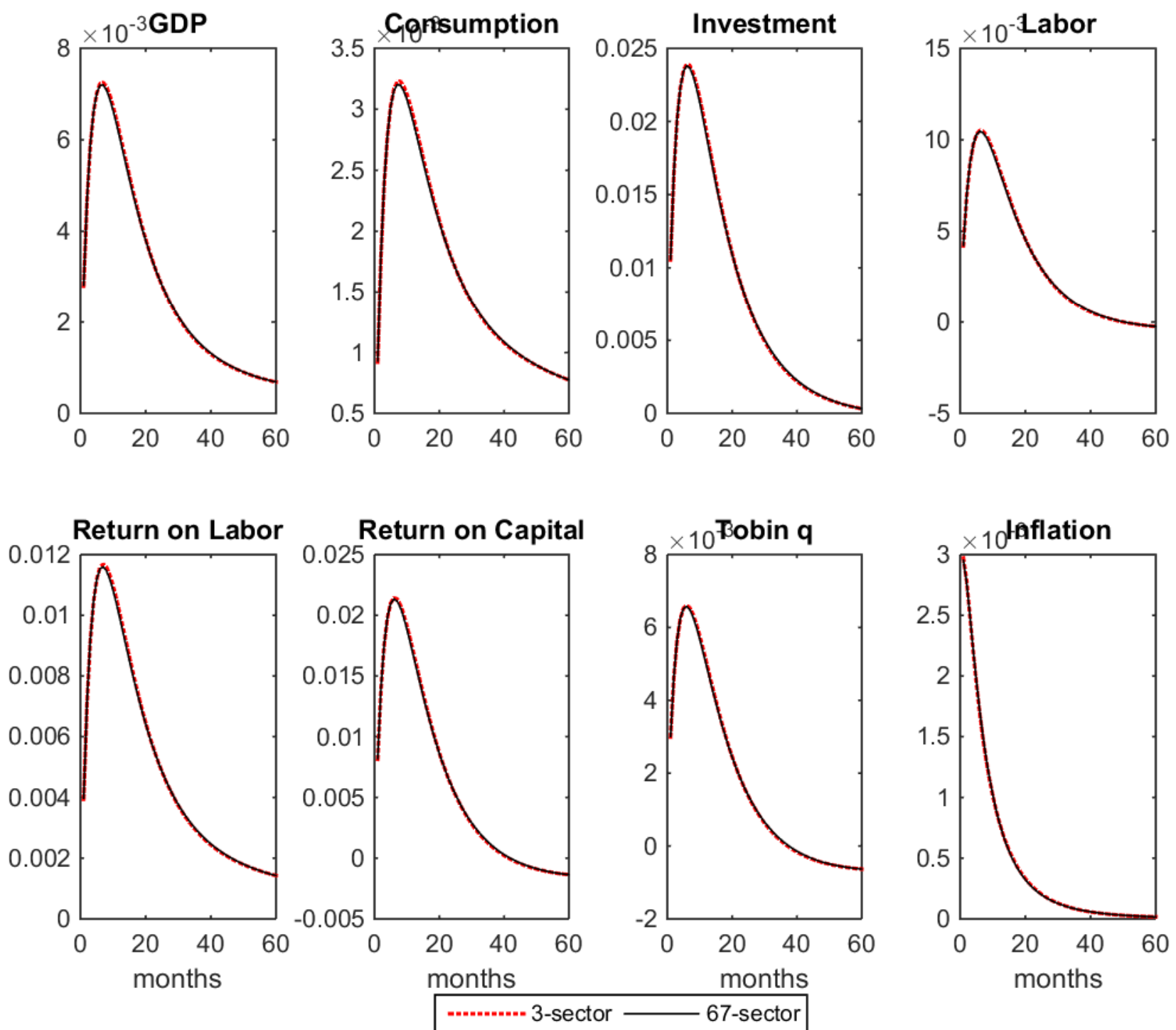

Figure A1: Impulse response functions in the 67-sector and the approximate three-sector economies - sector-specific factor markets: monetary shock. 

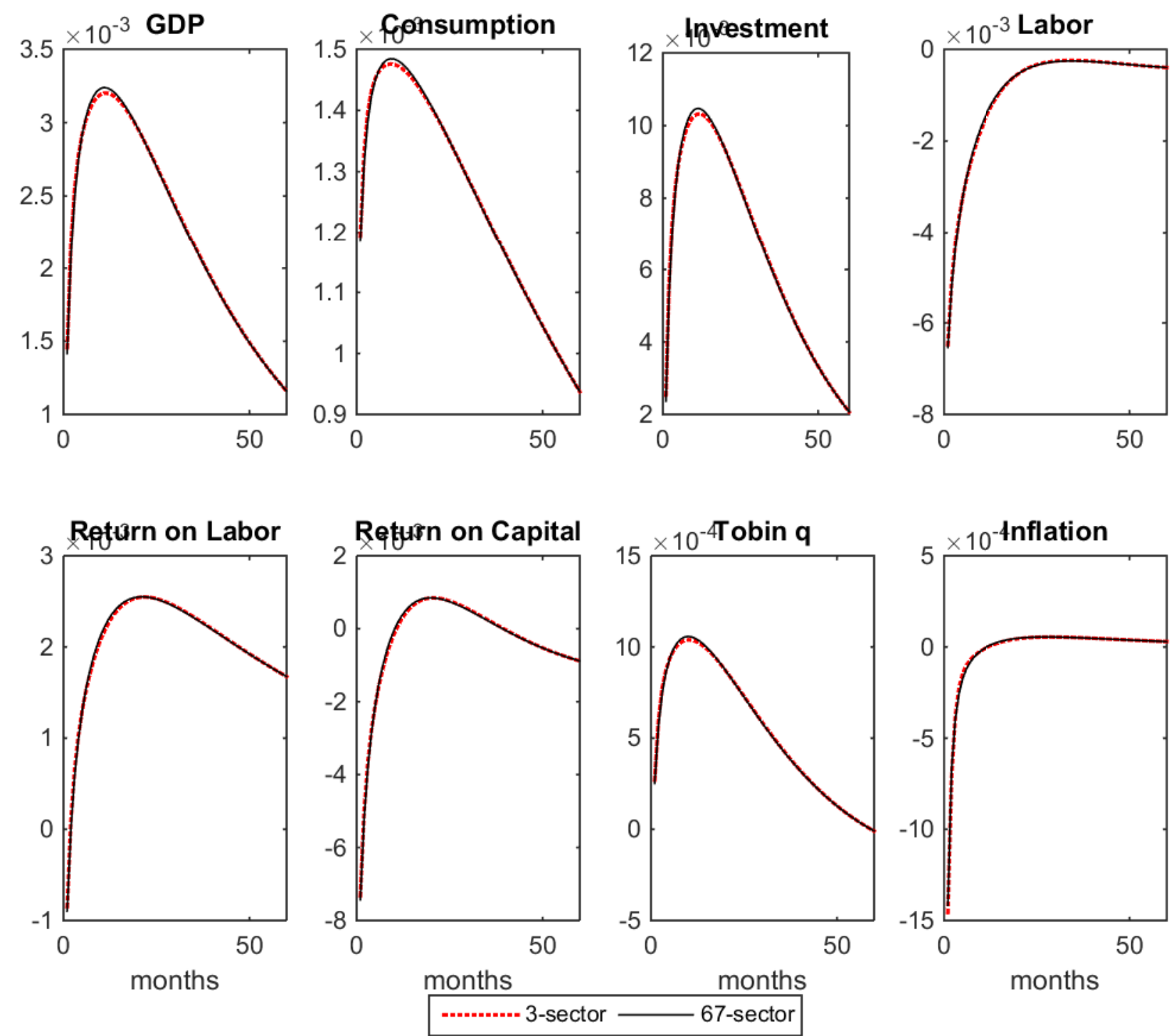

Figure A2: Impulse response functions in the 67-sector and the approximate three-sector economies - sector-specific factor markets: technology shock. 

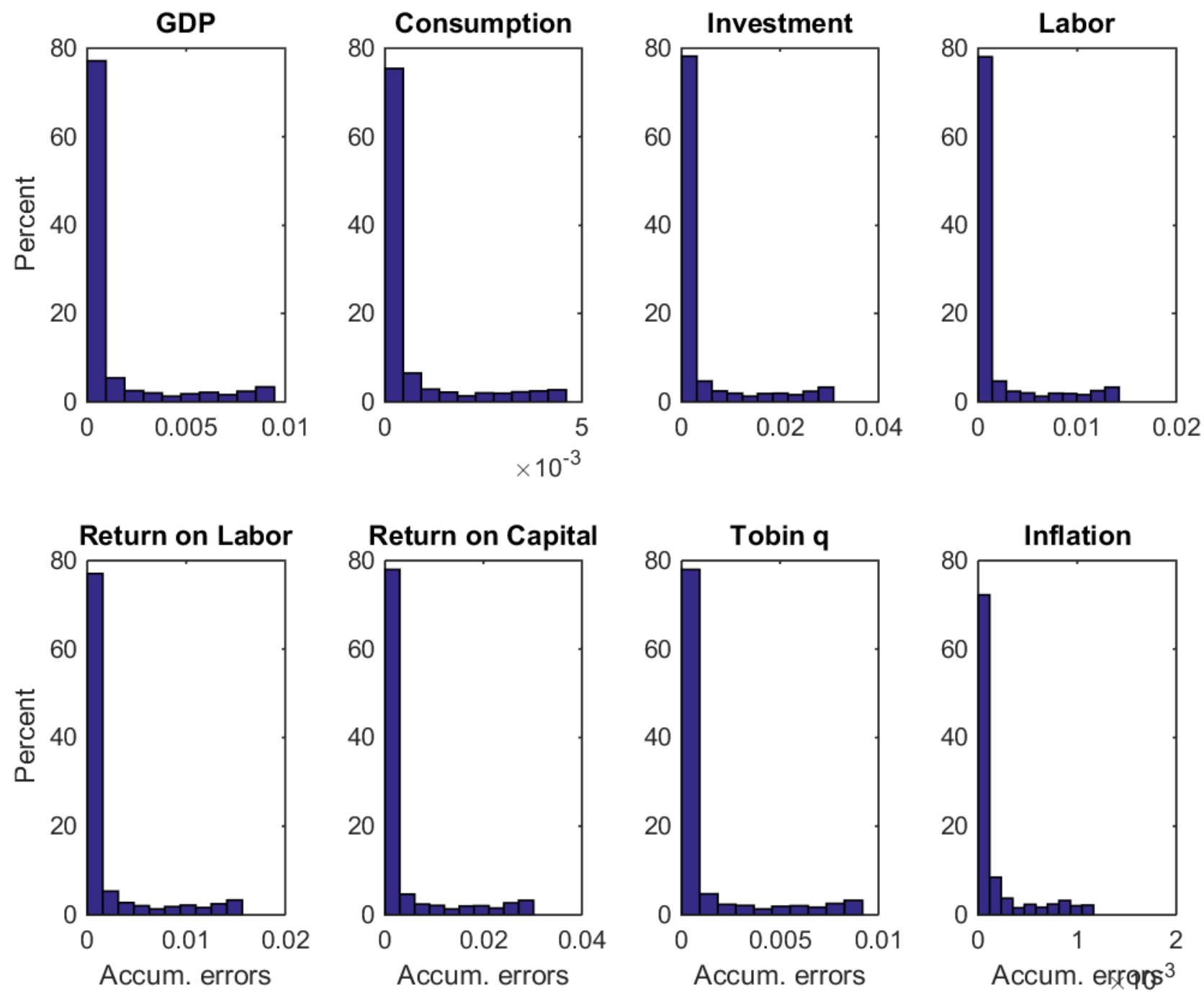

Figure A3: Distribution of cumulative approximation errors - sector-specific factor markets: monetary shock. 

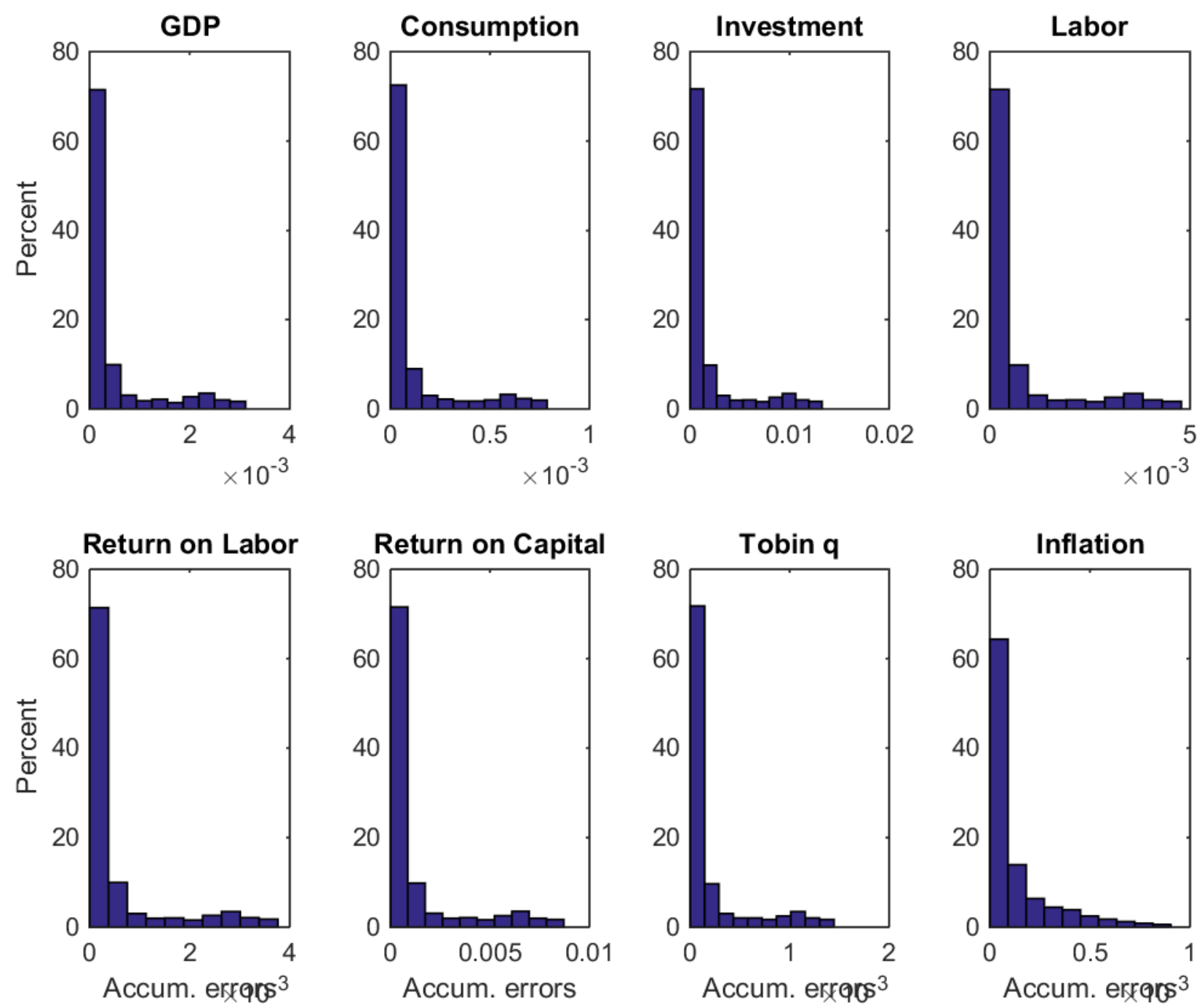

Figure A4: Distribution of cumulative approximation errors - sector-specific factor markets: technology shock. 